СОСТОЯНИЕ ЦЕНТРАЛЬНОЙ ГЕМОДИНАМИКИ, ВНУТРИЧЕРЕПНОГО И ЦЕРЕБРАЛЬНОГО ПЕРФУЗИОННОГО ДАВЛЕНИЙ ПРИ ОСТРЫХ НАРУШЕНИЯХ МОЗГОВОГО КРОВООБРАЩЕНИЯ

\author{
К. В. Лукашев ${ }^{1}$, А. З. Валиахмедов ${ }^{1}$, Ю. А. Чурляев ${ }^{1}$, Л. Ю. Редкокаша \\ Т. И. Борщикова ${ }^{2}$, П. Г. Ситников ${ }^{1}$, Т. П. Айкина ${ }^{2}$ \\ ${ }^{1}$ ГУ НИИ общей реаниматологии РАМН (Филиал), Новокузнецк, \\ ${ }^{2}$ МЛПУ Городская клиническая больница №1, Новокузнецк
}

\title{
Central Hemodynamics and Intracranial and Cerebral Perfusion Pressures in Acute Cerebral Circulatory Disorders
}

\author{
K. V. Lukashev' ${ }^{1}$, A. Z. Valiakhmedov ${ }^{1}$, Yu. A. Churlyaev ${ }^{1}$, L. Yu. Redkokasha², \\ T. I. Borshchikova², P. G. Sitnikov', T. P. Aikina ${ }^{2}$
}

${ }^{1}$ Branch of the Research Institute of General Reanimatology, Russian Academy of Medical Sciences;

${ }^{2}$ City Hospital One, Novokuznetsk

\begin{abstract}
Цель исследования - изучить состояние центральной гемодинамики (ЦГД), внутричерепного (ВЧД) и церебрального перфузионного давления (ЦПД) при острых нарушениях мозгового кровообращения (ОНМК) и взаимоотношений между ними для дальнейшей разработки интенсивной дифференцированной терапии выявленных нарушений. Материал и методы. Исследование состояния ЦГД методом транспульмональной термодилюции, измерение ВЧД, расчет ЦПД и рентгенологические исследования проведены у 18-и больных в 1-е, 3-и, 5-е и 7-е сутки острого периода ОНМК. У всех пациентов выявляли гипертоническую болезнь и ишемическую болезнь сердца. Результаты. В первые 5 суток ОНМК при геморрагическом инсульте (ГИ) отмечался нормодинамический тип кровообращения, а при ишемическом инсульте (ИИ) - гиподинамический. ВЧД в группе с ИИ оставалось на исходно повышенном уровне, а при ГИ в динамике нарастало. ЦПД достоверно не изменялось. Дисфункция миокарда выявлялась при достаточной преднагрузке за счет высокой постнагрузки. При ИИ выявлялась обратная корреляция между ВЧД и глобальной фракцией изгнания (ГФИ), индексом функции сердца (ИФС), а с 7-х суток - прямая корреляция. При геморрагическом инсульте ВЧД имело прямую связь с ИФС и обратную с ГФИ. Эти изменения на фоне лечения не прогрессировали и выявлялись на фоне дислокации головного мозга, что подтверждалось данными спиральной компьютерной томографии. Заключение. Таким образом, характер нарушения ЦгД зависит от вида ОНМК. В первые 5 суток острого периода при ИИ регистрируется гипокинетический тип кровообращения, а при геморрагическом - нормокинетический. Одной из причин изменений центральной гемодинамики является развитие дислокации головного мозга с нарушением функции его стволовых структур вследствие нарастания внутричерепного давления. Величина ВЧД при остром нарушении мозгового кровообращения является определяющим показателем в диагностике вторичных повреждений головного мозга и определяет тактику лечения. Ключевые слова: острое нарушение мозгового кровообращения, внутричерепное давление, церебральное перфузионное давление, центральная гемодинамика, депрессия миокарда.
\end{abstract}

Objective: to study the central hemodynamics (CH) and intracranial and cerebral perfusion pressures (ICP and CPP) in acute cerebral circulatory disorders (ACCD) and their possible relationships for further development of intensive differential therapy for the detected disorders. Material and methods. Hemodynamic studies using the transpulmonary thermodilution technique, measurements of ICP, calculations of CPP, and currently available X-ray studies were conducted in 18 patients on days 1, 3, 5, and 7 of ACCD. All the patients were found to have essential hypertension and coronary heart disease. Results. In the first 5 days of ACCD, there was a normodynamic type of circulation in hemorrhagic stroke (HS) and a hypodynamic type in ischemic stroke (IS). ICP remained at the baseline elevated level in the IS group and increased over time in the HS group. CPP was significantly unchanged. Myocardial dysfunction was detected when there was a significant preload caused by a high postload. In IS, an inverse correlation was found between ICP and global ejection fraction (GEF), cardiac performance index (CPI) and on day 7, the correlation was direct. In HS, ICP had a direct correlation with CPI and an inverse correlation with GEF. These changes during treatment failed to progress and were revealed in the presence of brain dislocation, as evidenced by spiral computed tomography. Conclusion. Thus, the pattern of $\mathrm{CH}$ disorders depends on the type of ACCD. In the first 5 days of ACCD, a hypokinetic circulatory type is registered in IS and a normokinetic type is in HS. Evolving dislocation of the brain with impaired function of its stem structures due to ICP elevation is one of the causes of central hemodynamic changes. The value of ICP in ACCD is a crucial indicator in the diagnosis of secondary brain dam-

Адрес для корреспонденции (Correspondence to):

Чурляев Юрий Алексеевич

Email: gunii@kuz.ru ages and determines treatment policy. Key words: acute ischemic attack, intracranial pressure, cerebral perfusion pressure, central hemodynamics, myocardial depression. 
Одной из первоочередных задач интенсивной терапии при церебральных катастрофах является создание условий для максимального уменьшения выраженности вторичного повреждения головного мозга. Достигается это, прежде всего, поддержанием адекватной перфузии головного мозга, а ее определяют гемодинамическая стабильность, адекватная искусственная вентиляция легких, нормализация внутричерепного давления (ВЧД), следовательно, и церебрального перфузионного давления (ЦПД) [1].

Острое нарушение мозгового кровообращения (ОНМК) всегда изменяет центральную гемодинамику (ЦГД). Основным мониторируемым показателем Цгд в реаниматологии является среднее артериальное давление (САД). САД - это интегральный показатель, являющийся производным от сердечного выброса, ОЦК, общего периферического сопротивления сосудов. Их динамика в остром периоде инсульта изучена недостаточно [2]. Литературные данные о состоянии и взаимосвязи гемодинамических параметров и ВЧД, ЦПД при острых нарушениях мозгового кровообращения неоднородны и, зачастую, противоречивы, нет единого представления о значимости ВЧД и ЦПД как диагностических критериев [2, 3]. Поэтому вопрос изменений ЦГД, ВЧД и ЦПД остается актуальным. Выявление возможных взаимосвязей между ними при ОНМК позволит скорректировать интенсивную терапию и, в конечном счете, повлиять на прогноз заболевания.

Цель исследования - изучить состояние центральной гемодинамики, ВЧД и ЦПД при острых нарушениях мозгового кровообращения и взаимоотношений между ними для дальнейшей разработки тактики интенсивной дифференцированной терапии выявленных нарушений.

\section{Материалы и методы}

Было исследовано 18 больных в 1-е, 3-и, 5-е и 7-е сутки острого периода ОНМК. В зависимости от типа инсульта их разделили на две группы. Группу I составили 10 человек с ишемическим инсультом (55,6\%), II -8 человек с геморрагическим инсультом (44,4\%). Средний возраст в первой группе составил $60,6 \pm 3,2$ года, во второй $-52,8 \pm 1,6$ года.

В 1-е сутки степень утраты сознания по шкале комы Глазго (ШКГ) при ишемическом инсульте оценивали в 7,8土0,8 и $7,1 \pm 0,4$ баллов при геморрагическом инсульте, а на 7 -е, соответственно, $-6,7 \pm 1,2$ и $6,3 \pm 0,7$ баллов [4]. Для объективизации тяжести состояния использовали балльную систему АРАCHЕ II, согласно которой тяжесть состояния больных в I группе оценивалась в $19,4 \pm 2,3$ баллов, а во II - в 16,7 $\pm 2,1$ баллов [5]. При поступлении диагностировали аспирацию желудочного содержимого в трахеобронхиальное дерево у 6-и человек $(33,3 \%)$. В анамнезе у всех пациентов регистрировали гипертоническую болезнь (ГБ) и ишемическую болезнь сердца (ИБС). В дальнейшем у 11 -и пациентов развилась пневмония, из них у 7-х (38,9\%) это происходило на фоне ОРДС I и ІІ стадии по классификации, предложенной В. В. Морозом и А. М. Голубевым [6]. Летальность в течение первых 7-и суток составила 27,8\% (5 человек), патологоанатомическое исследование регистрировало у них ОРДС без признаков развития пневмонии.

Всем поступившим выполнялось комплексное обследование, включающее клиническую оценку неврологического статуса, нейрофизиологические (акустические стволовые вы- званные потенциалы с помощью многофункционального компьютерного комплекса «Нейрософт», Россия) и рентгенологические (компьютерная томография на аппарате «Somaton Sensation» фирмы «Siemens», Германия) методы, исследования газового состава артериальной и венозной крови, гемостаза, клинические и биохимические показатели крови, мочи и ликвора [7].

Субдуральный/интрапаренхиматозный датчик внутричерепного давления «Codman» фирмы «Jonson \& Jonson» (Великобритания) устанавливали в первые сутки развития ОНМК и проводили мониторинг внутричерепного давления в режиме реального времени с расчетом церебрального перфузионного давления по общепринятой формуле: ЦПД = САД - ВЧД $[1,2,8]$.

Измерение гемодинамических показателей осуществляли с помощью транспульмональной термодилюции на базе системы мониторинга «PICCO plus» фирмы «PULSION medical system» (Германия). Анализировали следующие измеряемые и расчетные параметры центральной гемодинамики (ЦГД): среднее артериальное давление (САД, мм рт. ст.), сердечный индекс (СИ, л/мин $\left./ \mathrm{m}^{2}\right)$, индекс системного сосудистого сопротивления (ИССС, дин $\bullet \cdot \bullet^{-5} \mathbf{M}^{-5} \mathrm{M}^{2}$ ), индекс глобального конечного диастолического объема (ИГКДО, мл/м²), глобальную фракцию изгнания (ГФИ, \%), индекс внутригрудного объема крови (ИВОК, мл/м²), индекс функции сердца (ИФС, 1/мин), индекс сократимости левого желудочка (dPmax, мм рт. ст/сек), частоту сердечных сокращений (ЧСС, уд/мин).

Показаниями для применения инвазивных методов исследования являлись степень утраты сознания 8 и менее баллов по ШКГ и крайне тяжелое состояние больных, требующее контроля состояния показателей центральной гемодинамики и ВЧД для профилактики и лечения вторичных повреждений головного мозга $[1,8]$ и контроля проводимой инфузионнотрансфузионной терапии [9]. Регистрацию показателей центральной гемодинамики и ВЧД проводили одновременно каждые 8 часов.

Интенсивная терапия включала в себя общие мероприятия, направленные на поддержание жизненно важных органов и систем организма - искусственную вентиляцию легких современными микропроцессорными респираторами РВ-840 (Puritan-Bennet, CШA), MAQUET Servo-s (Maquet Critical Care AB, Швеция), Chirolog SV $\alpha$ (Chirana, Словакия), в соответствии с концепцией «безопасной ИВЛ» [10], профилактику и лечение инфекционных осложнений, нутритивную поддержку; и специфические - защиту головного мозга, нормализацию мозгового кровообращения, предупреждение и лечение отеканабухания мозга. Дополнительно для ишемического инсульта использовали нейропротекторы, антикоагулянты, препараты, улучшающие реологию, а для геморрагического - гемостатическую терапию [7]. Инотропную/вазопрессорную поддержку проводили по показаниям (начиная с $3-5$-х суток, 14-и пациентам $(77,8 \%)$ требовалось введение дофамина с целью поддержания системной гемодинамики в дозе до $11,4 \pm 2,1$ мкг/кг/мин). Объем гидратации за сутки составлял от 30 до 38 мл/кг массы тела.

Статистическую обработку полученных данных провели с помощью пакета сертифицированных программ GraphPad InStat 3 и Microsoft Office Excel 2003. Вычисляли среднеарифметические величины $(M)$ и стандартное отклонение средней $(\delta)$, достоверность оценивали по критерию Манна - Уитни и коэффициенту ранговой корреляции Спирмена. Отличия считали достоверными при $p<0,05$ [11].

\section{Результаты и обсуждение}

Повышенное ВЧД без достоверных изменений на протяжении всего периода исследования выявлялось в I группе, а при геморрагическом инсульте, оно было статистически достоверно выше и значимо возрастало с 3-х 


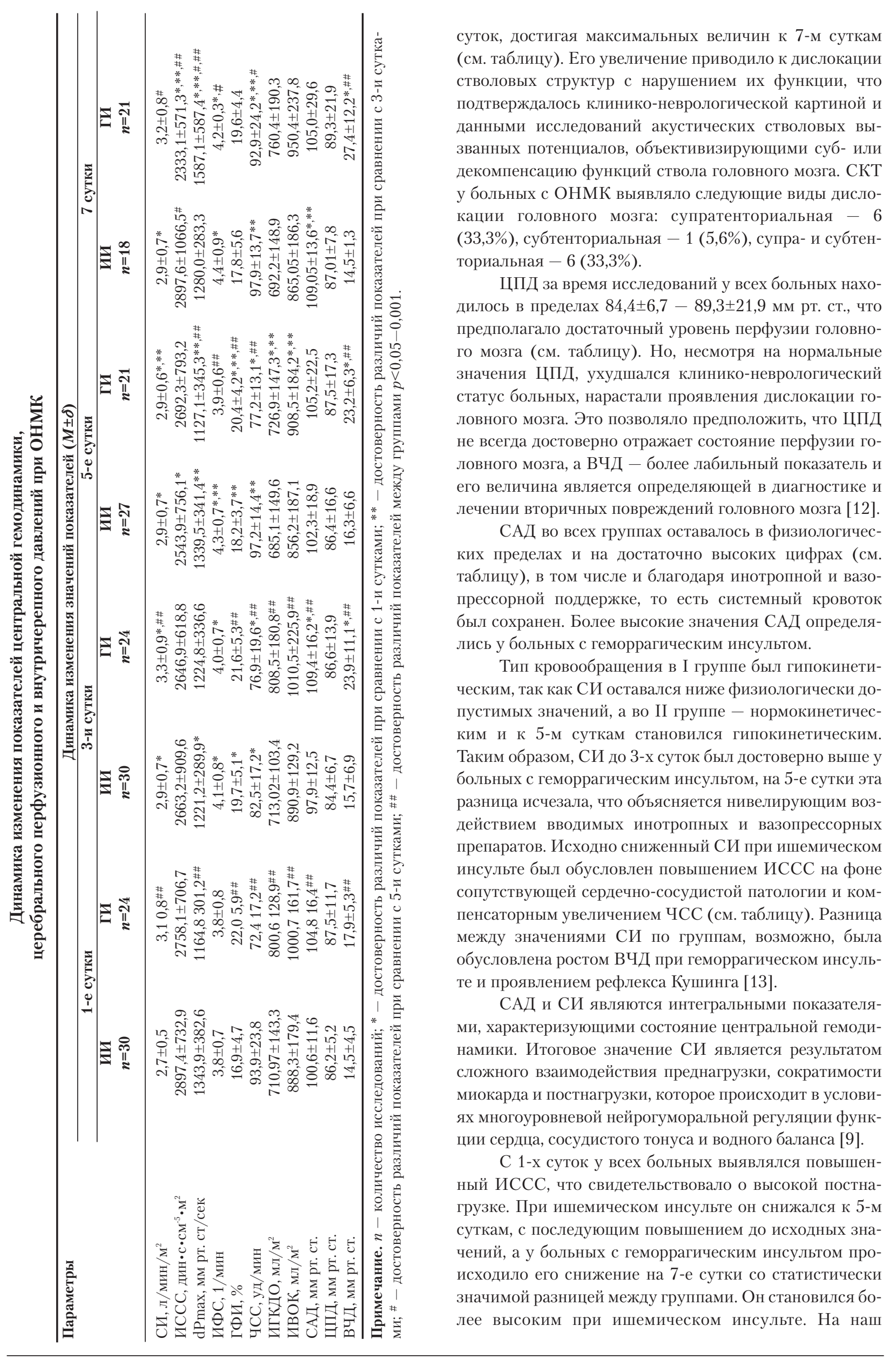




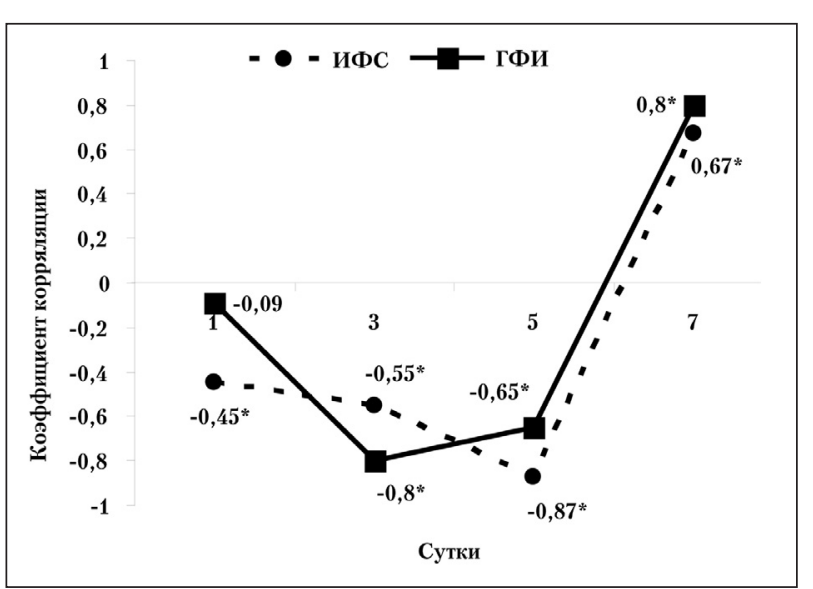

Рис. 1. Изменения коэффициента ранговой корреляции Спирмена в зависимости от суток исследования между ВЧД и ИФС, ВЧД и ГФИ при ишемическом инсульте.

взгляд, повышение ИССС было обусловлено не только сопутствующей сердечно-сосудистой патологией, но и развитием вследствие дислокации стволовых структур головного мозга патологической стимуляции прессорных зон, то есть повышения нейрогенного сосудистого тонуса $[1,7,14,15]$.

ИФС, ГФИ и dPmax отражают сократительную способность сердца. ИФС и ГФИ зависят не только от сократимости миокарда, но и от постнагрузки [9]. Их снижение у всех пациентов свидетельствовало о наличии признаков сердечной недостаточности. ИФС вследствие проводимой интенсивной терапии достоверно повышался на 3-и сутки. Его более высокое значение отмечалось в I группе на 5-е сутки проведения исследований. Сниженная ГФИ при ишемическом инсульте повышалась к 3-м суткам и в дальнейшем возвращалась до исходных значений. У больных с геморрагическим инсультом её значения были более высокими с 1-х суток исследований. ГФИ была достоверно выше при геморрагическом инсульте до 5-х суток, а на 7-е различия между группами исчезали. dPmax в I группе оставался в пределах нормальных значений с достоверным снижением на 3-и и повышением на 5-е сутки, во II группе сниженный индекс сократимости левого желудочка достоверно повышался к 7-м суткам. На 3-и и 5-е сутки dPmax был выше при ишемическом, а на 7-е - при геморрагическом инсульте (см. таблицу).

ИГКДО и ИВОК, отражающие истинную объемную преднагрузку, в обеих группах сохранялись в пределах допустимых физиологических значений, но в 1-е и 3-и сутки при геморрагическом инсульте они были достоверно выше, без различий в последующие сутки (см. таблицу).

Таким образом, в 1-е сутки у всех больных диагностировалась депрессия сократительной функции миокарда при достаточной преднагрузке - признаки сердечной недостаточности, к развитию которой приводило не только наличие ИБС и ГБ, но и компенсаторное повышение ИССС. В дальнейшем, на фоне проводимого лечения, нарушение сократительной способности сердца не прогрессировало, на что указывали

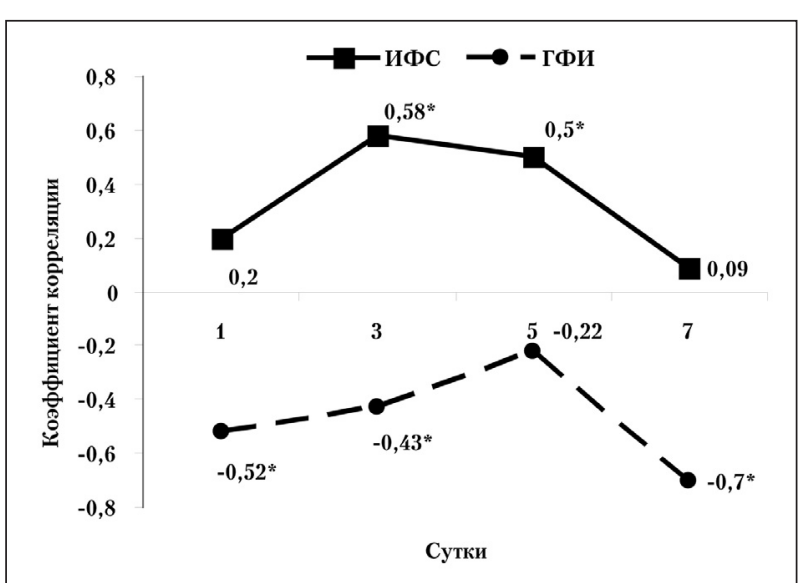

Рис. 2. Изменения коэффициента ранговой корреляции Спирмена в зависимости от суток исследования между ВЧД и ИФС, ВЧД и ГФИ при геморрагическом инсульте.

разнонаправленные изменения и колебания ИФС и ГФИ (табл. 1) [9].

Известно, что рост ВЧД происходит с момента возникновения ОНМК. Его повышение сопровождается дислокацией головного мозга и от того, на каком уровне происходит повреждение стволовых структур, возникают либо прессорные реакции (область четверохолмия), либо депрессорные (нижние отделы ствола головного мозга) [1, 14]. При прессорных реакциях происходит подъем АД за счет увеличения ИССС, что является компенсаторной реакцией на ишемию головного мозга, особенно его стволовых структур. Механизмы компенсации заключаются в усилении $\alpha$-адренергической стимуляции и вследствие этого резкого повышения нейрогенного тонуса сосудов $[1,7,15]$. Однако увеличение постнагрузки на фоне имеющейся ИБС и ХСН приводит к депрессии сократительной функции миокарда. В дальнейшем нарастание отека, рост ВЧД и дислокация головного мозга приводят к нарушению функции стволовых структур и, как следствие, возникает дисфункция сердечно-сосудистой деятельности [15].

При расчете ранговой корреляции Спирмена в 1-е, 3-и, 5-е сутки у пациентов с ишемическим инсультом высокое ВЧД сопровождалось снижением показателей сократимости сердца (ГФИ, ИФС), а на 7-е сутки - повышением, что объяснялось проведением интенсивной терапии, включающей в себя инотропную поддержку (рис. 1). При геморрагическом инсульте рост ВЧД сопровождался увеличением ИФС и уменьшением ГФИ на фоне проявлений рефлекса Кушинга (рис. 2). Следовательно, при геморрагическом и ишемическом инсультах имеется дисфункция сердечной деятельности, характер её зависит от вида ОНМК, что связано с нарушением функции стволовых структур головного мозга, вследствие дислокации на фоне высокого ВЧД.

\section{Заключение}

Таким образом, характер нарушения центральной гемодинамики зависит от вида острого нарушения 
мозгового кровообращения. В первые 5 суток острого периода при ишемическом инсульте регистрируется гипокинетический тип кровообращения, а при геморрагическом - нормокинетический. Одной из причин изменений центральной гемодинамики является развитие дислокации головного мозга с нарушением

\section{Литература}

1. Мороз В. В., Чурляев Ю. А. Вторичные повреждения головного мозга при тяжелой черепно-мозговой травме. М.; 2006.

2. Громов В. С., Белкин А. А., Левит А. Л. К вопросу о взаимоотношении центральной и церебральной гемодинамики при внутричерепной гипертензии. Сибирский мед. журн. 2006; 3 (21): 178-183.

3. Lang E. W., Lagopoulos J., Griffith J. et al. Cerebral vasomotor reactivity testing in head injury: the link between pressure and flow. J. Neurol. Neurosurg. Psychiatry 2003; 74 (8): 1053-1059.

4. Teasdale P., Jennett B. Assessment of coma and impaired consciousness. Lancet 1974; 2 (13): 1-84.

5. Knaus W. A., Draper E. A., Wagner D. P., Zimmerman J. E. APACHE II: a severity of disease, classification system. Crit. Care Med. 1985; 13 (10): 818-829.

6. Мороз В. В., Голубев А. М. Классификация острого респираторного дистресс-синдрома. Общая реаниматология 2007, III (5-6): 7-9.

7. Усенко Л. В., Мальцева Л. А. Нейрореаниматология: нейромониторинг, принципы интенсивной терапии, нейрореабилитация. Монография. Днепропетровск; 2008.

8. Башкиров М. И., Шахнович А. Р., Лубнин А. Б. Внутричерепное давление и внутричерепная гипертензия. Рос. журн. анестезиологии и интенс. терапии 1999; 1: 56-61. функции стволовых структур вследствие нарастания внутричерепного давления. Величина ВЧд при остром нарушении мозгового кровообращения является определяющим показателем в диагностике вторичных повреждений головного мозга и определяет тактику лечения.

9. Кузьков В. В., Киров М. Ю. Инвазивный мониторинг гемодинамики в интенсивной терапии и анестезиологии. Монография. Архангельск; 2008.

10. Сатишур O. Е. Механическая вентиляция легких. М.: Мед. лит.; 2006.

11. Платонов A. E. Статистический анализ в медицине и биологии: задачи, терминология, логика, компьютерные методы. М.: Изд-во PAMH; 2000

12. Белкин A. А. Патогенетическое понимание системы церебральной защиты при внутричерепной гипертензии и пути ее клинической реализации у больных с острой церебральной недостаточностью. Интенс. терапия 2006; 3 (7): 127-134.

13. Cushing $H$. Experimental and clinical observations concerning states of increased intracranial pressure. Am. J. Med. Sci. 1902; 124: 375-400.

14. Зотов Ю. В., Щедрёнок В. В. Хирургия травматических внутричерепных гематом и очагов размножения головного мозга. Л.: Медицина; 1984.

15. Михайлов В. В. Основы патологической физиологии: Руководство для врачей. М.: Медицина; 2001.

Поступила 07.04.09
CSA Fall Hawaiian Seminar

October, 26-30, Poipu Beach, Kauai

www.csahq.org

AAGBI Regional Core Topics Programme 2009

October, 29, Glasgow, UK

www. aagbi. org/events/acthtm info@aagbi.org

AAGBI Regional Core Topics Programme 2009

November, 4, Nottingham, UK

www.aagbi.org/events/act.htm info@aagbi.org

AAGBI Regional Core Topics Programme 2009

November, 25, Nottingham, UK

www. aagbi. org/events/act.htm info@aagbi.org

63 ${ }^{\text {rd }}$ PostGraduate Assembly in Anesthesiology (PGA)

December, 11-15, New York, USA

HQ@nyssa-pga.org

https://nyssa-pga. net
CSA Winter Hawaiian Seminar

January, 18-22, Ka'anapali Beach, Maui www.csahq.org

NYSORA World Anesthesia Congress (NWAC)

March, 7-12, Dubai, United Arab Emirates

www. nysoraworld.com

pat.pokorny@nysoraworld.com

CSA Annual Meeting and Clinical Anesthesia Update May, 14-16, Costa Mesa, California, USA www.csahq.org

Euroanaesthesia 2010

June, 12-15, Helsinki, Finland

www.euroanesthesia.org

secretariat@euroanesthesia.org

CSA Fall Hawaiian Seminar

November, 1-5, Kona, Hawai www.csahq.org 